\title{
O CLUBE DOS POETAS MORTOS OU OH CAPTAIN, MY CAPTAIN!... Carpe Diem.... Memórias da sociedade e de ensino de ontem para a sociedade de ensino de hoje e de amanhã numa nova ordem digital.
}

\author{
THE DEAD POETS SOCIETY OR OH CAPTAIN, MY CAPTAIN!... \\ Carpe Diem.... Memories of yesterday's teaching society for today's and \\ tomorrow's teaching society in a new digital order.
}

Isabel Lousada ${ }^{1}$
Vanda Sousa $^{2}$

\section{Resumo:}

Tomando como ponto de partida a análise do texto fílmico O Clube dos Poetas Mortos, a atual proposta visa contrapor uma determinada representação fílmica do Ensino e da Sociedade, datada do final da década de cinquenta do século passado, para discutirmos se, no atual momento do desenvolvimento das Tecnologias da Informação e Comunicação e, na vigência de uma não linearidade e da Hiper textualidade, a relação docente/discente se mantém, se a ecoa ou se sofreu uma (profunda) alteração. Julgamos estar em condições de demonstrar que, no essencial, a relação ontológica e fenomenológica se mantém. Tendo as atuais tecnologias digitais produzido uma transformação social e cultural, pretendemos demonstrar que esta manifesta-se na forma como os conceitos, agora em análise, são operacionalizados.

Palavras-chave: Clube dos Poetas Mortos. Ensino. Sociedade. Era digital.

\begin{abstract}
:
Considering the film text Dead Poet Society as a starting point, we aim to debate the concepts of Teaching and Society, linked to a specific film representation dated from the 50-decade last century. Considering the actual development of Information and Communication Technologies and, in the presence of a non-linearity and hyper textuality, we will also consider to discuss whichever the relationship teacher/student expressed in the scrutinised film text, remains, echoes or disclose a (profound) transformation. We deem be able to validate that, essentially, the ontological and phenomenological relationship persists, although, the current digital technologies produced a social and cultural change, visible in the way those concepts are take on.
\end{abstract}

Keywords: Dead Poet Society. Teaching. Society. Digital Age.

\footnotetext{
1 Faculdade de Ciências Sociais e Humanas da Universidade Nova de Lisboa (CICSNOVA). Email: iclousada@gmail.com. ORCID:0000-0002-7652-8544.

2 ESCS - Escola Superior de Comunicação Social IPL - Instituto Politécnico de Lisboa. Email: vandamariasousa62@gmail.com . ORCID: 0000-0002-7676-0853.
} 


\section{RevistAleph}

\section{Introdução}

Muitos são os textos fílmicos que abordam a questão da Escola e da Sociedade e muitos são os que o fazem do ponto de vista da problemática disciplina vs. indisciplina. Não será esse o nosso foco na leitura que, agora, empreendemos de O Clube dos Poetas Mortos. Antes, a nossa reflexão enquadra-se no eixo relacionamento professor/aluno e a sociedade em que se insere.

Reportando ao final da década de cinquenta do século passado, a narrativa propõe um colégio caracterizado de forma particular, com valores, princípios e normas específicas e consonantes aos seus objetivos formativos de novos cidadãos. Assim, não só oferece uma leitura contextualizada no tempo (1959), como ainda se apresenta como uma leitura retrospectiva desse mesmo tempo: em 1989, o texto fílmico propõe-nos um olhar sobre determinado Ensino, em determinada Sociedade (classe média alta, norte-americana).

Nessas visões em palimpsesto, acrescentaremos agora a nossa, datada em primeiro lugar pela memória do primeiro contato com o texto fílmico, 1990; em segundo lugar, pela data do presente reencontro, 2020, ao mesmo tempo que nunca deixará de se ter presente que se trata de um olhar de uma sociedade latina sobre um texto anglosaxônico. Por muito que a Europa em geral, ou Portugal com a particularidade de ter adotado a legendagem em detrimento da dobragem, esteja habituado (invadido mesmo) pelo universo fílmico norte-americano, a geografia cultural nunca deixará de marcar a leitura do texto.

Escolhido o texto fílmico como texto e contexto da presente análise, salvaguardamos a legitimidade de apresentar a nossa leitura que, a ser assim e não deixando de reconhecer as múltiplas leituras semióticas que se entrecruzam, reconhecemos para lá da escola criticista ou mesmo da semiótica greimasiana, posicionando-nos numa abordagem de semiótica fílmica para a leitura de $O$ Clube dos Poetas Mortos. Com realização de Peter Weir, direção de fotografia de John Seale, a partir do argumento de Tom Shulman, e música de Maurice Jarre, O Clube dos Poetas Mortos, teve produção de Steven Haft, Paul Junger e Tony Thomas da Touchstone Pictures, Silver Screen Partners IV, Witt-Thomas Production e distribuição da Warner Bros.

O filme propõe-nos a história de um professor de literatura que regressa ao colégio onde se formou, contudo, desacredita dos métodos conservadores que orientam a 


\section{RevistAleph}

instituição. Ao tentar passar a sua máxima de vida, Carpe Diem (tornem as vossas vidas extraordinárias), acaba por desencadear, nos seus alunos, a vontade de viver e ser verdadeiro. A sua mensagem é transformadora, mas leva-nos a pensar no risco que se corre quando um dos seus alunos acaba por cometer suicídio.

\section{O Clube dos Poetas Mortos}

Está-se em 1959. Situado em Vermont, nos Estados Unidos da América, o colégio de Welton tem como missão formar as futuras elites, de acordo com os valores da tradição, disciplina, honra e da excelência, que surgem nos estandartes que os alunos seguram durante a cerimônia de abertura do ano letivo que conta com a presença dos pais, representando a sua adesão aos valores do colégio; o primeiro ato da narrativa abre com a apresentação, por parte do diretor (Nolan), do novo professor de inglês (John Keating) que, também fora aluno de Welton. Keating estabelece a sua personagem ao convidar os alunos a tratarem-no por "Oh Captain, my Captain!" (excerto de um poema de Whitman em honra de Lincoln). A narrativa é construída com uma cena de apresentação que propõe uma ligação entre Keating e o colégio: ao levar os alunos pelos corredores que exibem as fotografias dos antigos alunos, o professor apresenta a sua exuberante conceção de vida Carpe Diem...Tornem a vossa vida extraordinária!

O apelo à construção de uma vida extraordinária sustenta-se na conceção da poesia, mais do que arte, como própria do exercício da humanidade, como paixão.

Feita a apresentação, o primeiro ato prossegue com a construção dramática do primeiro ponto de viragem: a descoberta de um "Livro de Turma" que reportava ao tempo em que Keating era aluno em Welton. Esta ação é seguida de uma cena de explicação, o professor revela aos alunos que pertencia ao Clube dos Poetas Mortos - um grupo de estudantes que se reunia clandestinamente numa gruta e que ansiava viver intensamente a vida.

Um grupo de alunos, de que fazem parte Neil Perry, Charlie Dalton, Knox Oversteet, Meeks, Pitts, Cameron ou Todd, recuperam a prática dessas reuniões, onde se leem poemas, se contam histórias, se ouve música, se canta, se fuma e se dança.

Para Keating, a vida extravasa o padrão e só é verdadeiramente vivida e compreendida quando é olhada por diferentes prismas, isso mesmo demonstra quando 


\section{RevistAleph}

convida os alunos a ficarem de pé em cima das carteiras, desta forma, alterando a perspectiva pela qual vêem o que os rodeia, ou mesmo as palavras (no caso, a escrita de Shakespeare) podem ser olhadas e compreendidas de forma diferente. No fundo, a máxima de vida de Keating repousa na recusa da aceitação imediata e convida à experiência pela paixão. Só o sentimento verdadeiro e livre poderá libertar a poesia que cada um de nós encerra em si mesmo. Isso é figurado na narrativa através do convite a que Todd solte um bravo grito, genuíno, catarse que se consumará na escrita de um poema original e que parecia impossível de acontecer.

Keating simboliza a recusa representada até pelas próprias paredes de Welton. Por isso, as suas aulas acontecem ao ar livre, sob o convite para que expressem a sua individualidade nem que seja pela forma como caminham. Para Keating, a vida é próxima ao conceito heideggeriano: no se a ontologia do Ser não se manifesta, o ente ou ser-aí (dasein) é o pastor do Ser, mas para isso, no exercício da linguagem não pode ser mera expressão do lugar comum, não pode perder-se na ausência da sua individualidade que, deve ser afirmada como condição mais do que existencial, ontológica mesmo (HEIDEGGER, 2009).

Esta afirmação do eu permite à narrativa a passagem para o segundo ato, numa vertigem para o clímax. A totalidade do segundo ato sustenta-se na afirmação de cada uma das convicções individuais em detrimento e em confronto com o socialmente aceito e desejado. Assim, Knox revela a sua paixão por Chris, Neil concretiza o seu sonho de ser ator contra a vontade do pai, Charlie escreve um artigo no jornal do colégio, assinando em nome de $O$ Clube dos Poetas Mortos, recusando a diferenciação de gênero no colégio - momento, particularmente interessante, dado que reforça a ausência feminina da e na narrativa. No presente texto fílmico foram dadas escusas ao feminino, tanto na ação dramática, quanto na representação, curiosamente, produzindo a afirmação de uma presença que pode ser lida na obcecante ausência.

O clímax avizinha-se: Charlie é ameaçado de expulsão caso não denuncie o Clube dos Poetas Mortos, Neil vai ser transferido para uma academia militar. Incapaz de suportar a imposição do pai, Neil suicida-se.

O terceiro ato da narrativa convoca-nos para o inquérito que recai sobre Keating e as acusações de que é alvo, culminando na sua expulsão de Welton. Nesta resolução do conflito dramático, o texto fílmico convoca à verdade dos seus valores, apesar das 


\section{RevistAleph}

consequências, a filosofia de vida de Keating é recuperada quando, ao se despedir dos alunos, na presença do diretor de Welton, os alunos se colocam de pé em cima das carteiras e o saúdam: Oh Captain, my Captain!

Não estando em causa o pretender-se levar a cabo uma leitura integral e crítica do texto fílmico, vamos recorrer aos elementos da gramática cinematográfica que acreditamos sublinharem as premissas ensino/sociedade que nos convocam à escrita, no presente momento. Para isso, vamos analisar a forma como a escala de planos, a regra dos eixos e os componentes dramáticos são usados, em ruptura com as regras clássicas, ao serviço da mensagem deste texto fílmico. Para tal, vamos analisar alguns planos que consideramos particularmente esclarecedores da mensagem que o filme carrega no que ao eixo ensino/sociedade diz respeito.

O texto abre à leitura em exorbitantes grandes planos dos rostos de alunos que encadeiam com o rosto do diretor Nolan para depois procurar e encontrar um grande plano de uma vela que arde à esquerda do ecrã. Pouco a pouco, a imagem faz deslocar a luz até que, num movimento descendente, a vela sai de campo. É, assim, feito o statement do texto: está-se num estabelecimento de ensino, alunos preparam-se para a aprendizagem que se faz representar pela luz da vela que se move saindo de campo, impondo-se, numa metáfora que legitima a leitura de um ensino aceito e em vigor na sociedade (pretensamente) luz da vela presente que, ao abandonar-se num movimento lento e descendente, permite a leitura do esmorecimento, do lento apagar (auto consumindo-se), de um ensino anterior (sabemos que sustentado na poesia e na paixão pela vida) e que, sendo arriscado (nas palavras de Keating, "não é fácil enfrentar os outros e afirmar a nossa própria forma de ser", pode destruir-nos (como sucederá com Neil).

Desta forma, o statement do texto fílmico fica claro desde os primeiros planos: consideram-se duas concepções de ensino (aqui estendido ao conceito de educação), uma que visa a integração em sociedade, a outra que visa o crescimento interior.

O texto fílmico mantém uma linguagem quase sufocante que surge na técnica de encadeados (difusos) de grandes planos mantendo-se a luz à esquerda do plano, o que nos abre a várias leituras: da esquerda para a direita o plano mantém a regra da panorâmica (ainda que o movimento não seja convocado), traduzindo a conformidade com a trajetória do Sol - de este a oeste/ de nascente a poente/ de ocidente a oriente, ou, a um outro nível, reproduzindo o movimento da escrita (da esquerda para a direita, de cima para baixo). 


\section{RevistAleph}

Por entre, o encadeado de grandes planos a imagem revela-nos os estandartes do colégio que os alunos transportam, para terminar a sequência num amorcé difuso e, ousadamente em grande plano, que obriga o espectador a uma entrada forçada na linha narrativa, que só permite a respiração quando fecha a sequência no plano que revela a entrada do colégio. A partir de um jogo de campo e contra campo, entramos, por fim, no colégio onde se vai realizar a cerimônia de abertura do ano letivo. Os elementos visuais estabelecem uma gramática que consolida a apresentação: os alunos, com os estandartes, descem as escadas para o anfiteatro, destacando-se num plano superior o diretor.

Na sequência da cerimônia, os planos médios que nos apresentam as personagens subvertem a escala de planos. O plano médio tradicional mostra a personagem da cabeça ao tronco. Aqui, o texto opta por enquadrar dos pés à cintura. Assim, antes que possamos ver as personagens que irão participar na cerimônia, em particular, os pais, começamos por as caracterizar pelo formalismo com que se apresentam (condizente com a data em que a narrativa decorre, 1959), mas omitindo-lhes, num primeiro momento, os rostos.

A sequência de abertura convoca-nos ainda a uma outra interrogação: o único feminino, presente ao texto fílmico, surge nesta sequência e em conformidade com a gramática audiovisual usada. Assim, as mães presentes na cerimônia, também elas, são representadas na subversão da escala de planos: começamos por ver-lhes os pés e pernas e, só depois nos é dado ver-lhes os rostos. O texto fílmico faz-se assertivo: mais do que mães que acompanham os pais na cerimónia de abertura do ano letivo dos filhos, elas são, antes de tudo, esposas. No contexto epocal e social que envolve a narrativa, as figuras femininas estão representadas de forma fiel. Vive-se ainda o boom económico do pós-guerra e das mulheres (sobretudo na classe média alta) de quem se espera sejam a ala passiva do casal. Não Ihes cabe tomarem parte nas decisões que dizem respeito ao ensino dos filhos, da mesma forma que não lhes cabe um papel ativo na sociedade. Espera-se que sejam esposas, numa sociedade que se movimenta, ainda, muito no masculino deixando o feminino num plano secundário. A representação da figura feminina no presente texto fílmico convoca a uma reflexão sobre o modo de representação da mulher; contudo, a forma como surgem na ação (vale dizer como não-ação) permite a leitura de uma negação do male gaze (Mulvey, 2009, p.59): a figura da mulher não é explorada, não é vista pelo olhar masculino (da realização), antes, pela gramática escolhida, pode concluir-se que é ostensivamente, apagada, feita adereço no enquadramento. 


\section{RevistAleph}

Em contraponto com a visibilidade, em grande plano, que nos é permitida aos rostos do diretor do colégio e restante corpo docente, o texto parece querer indiciar quais são as personagens que irão viver o enredo. Ainda nesta sequência, a vela (componente dramático de explicação) é transportada descrevendo uma trajetória da esquerda para a direita do enquadramento, sem que se perca o primeiro plano, tornando-a à leitura, como elemento catalisador da ação.

A ênfase é colocada no enquadramento em que nos é dado ver os alunos que se sentam e um dos alunos segura a vela erguendo-a e deixando-a no terço direito da imagem, estabelecendo uma interessante triangulação entre a luz e os rostos dos estudantes. 0 plano enquadra, no grande plano, um cruzamento de linhas de força que propõe a leitura de uma metafísica da luz (D’HOLLANDA, 1918), aqui, invertida. De resto, a luz da vela, na abertura, os candeeiros das salas de aula, e até a iluminação na gruta convocam a uma leitura e descodificação (METZ, 1980) que nos concede ler-se o ensino como crescimento.

A aula do professor Keating (primeiro ato) convoca-nos à reflexão em torno do eixo ensino/sociedade. A imagem (vide figura 1) revela-nos uma tradicional sala de aula. Poderíamos mesmo dizer que se trata de um estereótipo, não fora o destaque que é dado ao professor que ocupa o plano de forma que convoca uma leitura disruptiva da imagem (BARTHES, 2007). Keating apresenta-se, não formalmente, à secretária, mas antes, erguido, com um pé assente em cada uma das duas primeiras secretárias dos alunos da fila da frente. A sua atitude é desafiadora, mas convicta, numa metáfora do que se passa na cena (Oh Captain, my Captain! e a máxima Carpe Diem). A leitura do plano é clara: apesar de estar num ponto superior, mais alto, do que o olhar dos alunos, Keating não está acima deles, se essa fosse a intenção, o plano haveria de ser gravado em ponto de vista dos alunos e, inevitavelmente, num ângulo contrapicado. Ora, o plano enquadra Keating deixando os alunos sentados, a uma altura inferior, mas não construindo a vertigem de um olhar dirigido para uma altura superior. Três alunos são enquadrados, sentados, dirigem o olhar para Keating, todavia, na ausência do contrapicado a altura a que o professor se coloca, tornase mais um convite do que o estabelecimento de uma distância impossível de alcançar. 0 plano deve ser lido como um convite à ascensão e não como uma imposição de uma ascensão vedada ou impossível. É um convite à aprendizagem, à abertura ao ensino, aqui revelado como uma metáfora da mensagem fílmica: o ensino conservador exclui o sujeito e a individualidade, privilegiando a norma socialmente aceita. 


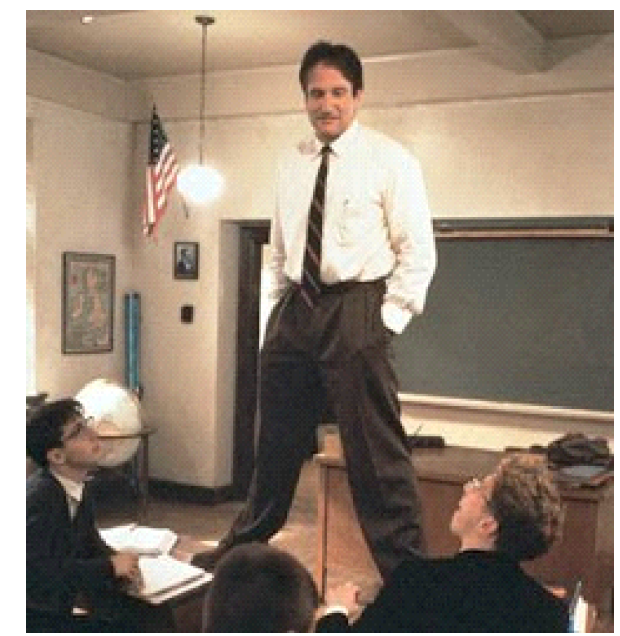

Figura 1. Fonte: https://www.youtube.com/watch?v=V1unMAruf1w

Este plano deve ser lido em justaposição com o plano seguinte (vide figura 2) que nos mostra a mesma sala de aula mas, agora, são os alunos que surgem, de pé, sobre as carteiras. O plano permite uma interessante leitura a partir do enquadramento escolhido: nem todos os alunos estão de pé. É-nos dado ver alunos sentados, formalmente, nas suas carteiras e, aparentemente, indiferentes aos colegas - diríamos ausentes da ação dramática; os alunos que podemos ver, sobre as carteiras, de pé, estão em cena numa arrojada distribuição que desenha um triângulo equilátero que é, ainda, sublinhado pela triangulação definida pelas luzes do candeeiro, convocando à leitura de uma presença em cena numa metáfora de uma atitude iniciática: ultrapassado o ritual (rasgar a introdução do livro sobre poesia e ousar subir e colocar-se de pé em cima das carteiras), os alunos estão aptos a receberem o verdadeiro ensino e afirmar a sua vontade mesmo que o professor já não esteja entre eles, tenha sido despedido da conservadora Welton (vide figura 3): aprender (ser objeto de ensino) em conjunto com os outros (em sociedade), mesmo que o processo seja individual, mesmo que o caminho seja o caminho de cada um, deve ser caminhado em comunhão. Neste sentido, pode ser lido o lema Carpe Diem que convoca, cada um, a fazer da sua vida algo de extraordinário, leia-se, extra-ordinário e isso está plasmado no plano que apresenta Keating, sentado informalmente e (informalmente) rodeado de alunos, inter pares. Quem aprende aprende o seu caminho, aprende em conjunto e somente na comunhão entre docente e discente se estará perante um ensino para a sociedade. 


\section{RevistAleph}

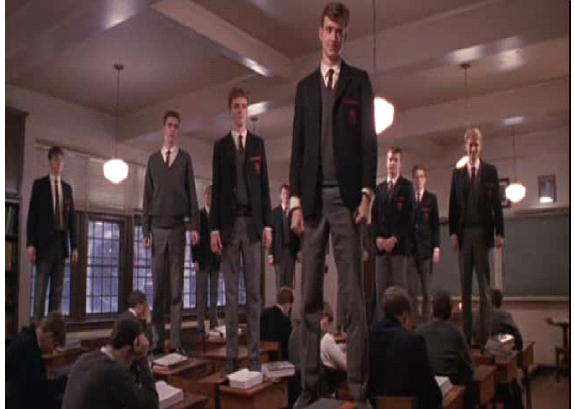

Figura 2. Fonte:

https://www.youtube.com/watch?v=V1unMAruf1w

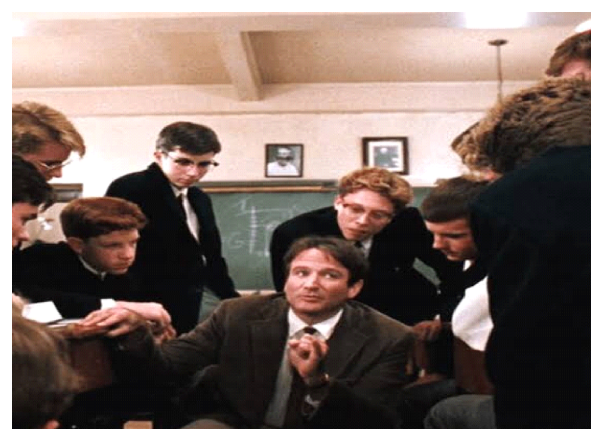

Figura 3. Fonte:

https://www.youtube.com/watch?v=V1unMAruf1w

Em O Clube dos Poetas Mortos, o ensino é lugar de troca entre docente e discente, o plano assume um ligeiríssimo picado, enquadrando os alunos sentados nas secretárias, dirigindo o olhar para o lugar tradicional do professor, deixando-nos perceber que esse lugar é ocupado por um dos alunos, o professor surge quase de joelhos, erguendo o olhar em direção ao estrado (vide figura 4).

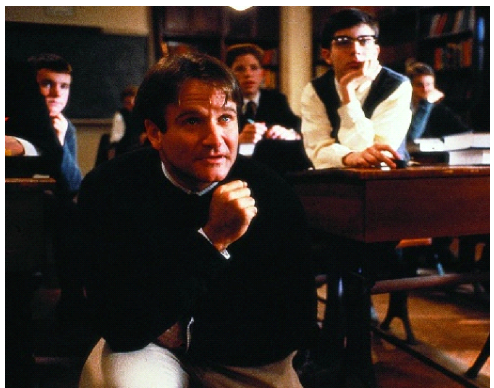

Figura 4. Fonte:

https://www.youtube.com/watch?v=V1unMAruf1w

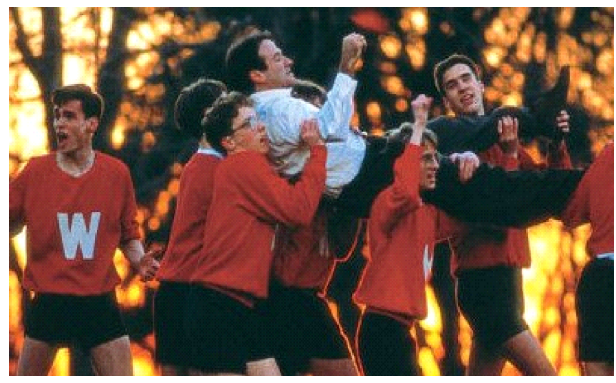

Figura 5. Fonte:

https://www.youtube.com/watch?v=V1unMAruf1w)

O ensino não está confinado nem à formalidade nem à sala de aula. Em $O$ Clube dos Poetas Mortos, o ensino é informal e paixão, porque de paixão é feita a poesia e o ser humano. A relação discente/docente é vista como uma relação de confiança, Keating faz-se (deixa-se) transportar, suportado pelos alunos que o seguram, erguido no ar, atravessando o pátio (vide figura 5). Lido como integração na sociedade, o ensino é feito de conhecimento, mas também de afetos, esse é o ensino conducente à inclusão.

Só um ensino que privilegie a relação entre docente e discente, que frutifique, não nos quatro pilares conservadores que caracterizam Welton, mas antes na liberdade de prossecução da sua própria identidade, pode conduzir à (auto)descoberta. Disso mesmo nos dá conta o texto fílmico quando nos apresenta a recriação do Clube levada a cabo pelos alunos, sem que o professor esteja a par disso (vide figura 6). 


\section{RevistAleph}

A gruta surge no texto fílmico quer como evocação da gruta da Alegoria da Caverna, de Platão, para quem a poesia seria a raiz de todos os males, e a partir da qual não poderíamos alcançar o conhecimento dos arquétipos, mas somente das sombras. O plano permite múltiplas leituras: os jovens replicam o esquecido Clube dos Poetas Mortos, mas fazem-no com música, com bebida e fumando. O plano regressa a um enquadramento que não se subtrai à metafísica da luz. A triangulação de luz feita a partir do exterior e, de modo mais cênico, no interior, permite construir uma mise-en-scène que evidencia tabaco, música nos dois terços, à esquerda do plano. Tomando a esquerda do plano, a imagem deixa em ponto de fuga a abertura da caverna que, não sendo visível, está claramente indiciada. Assim, o conhecimento, no interior da caverna poderá muito bem ser o do mundo das sombras, mas a possibilidade de sair da gruta e ir ao encontro do verdadeiro conhecimento, pertence ao livre arbítrio de cada um.

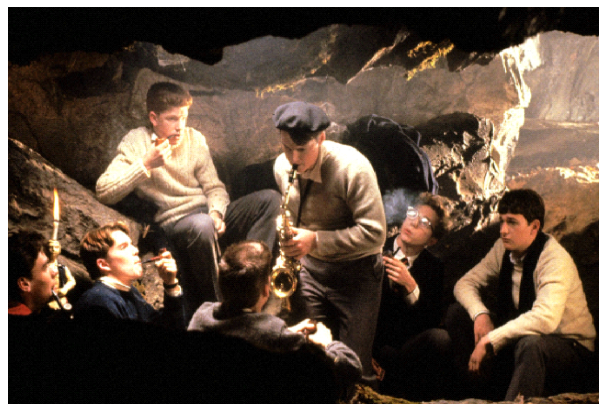

Figura 6. Fonte: https://www.youtube.com/watch?v=V1unMAruf1w)

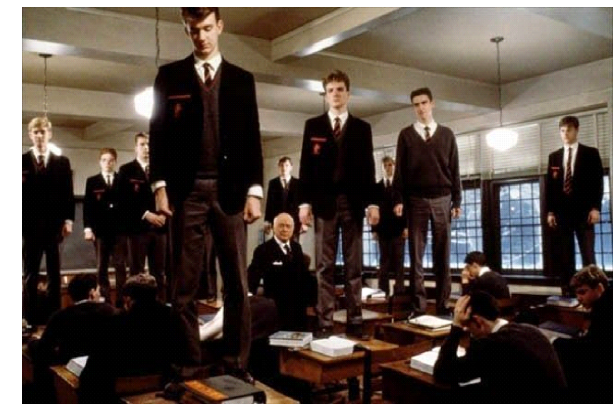

Figura 7. Fonte: https://www.youtube.com/watch?v=V1unMAruf1w)

O plano que ilustra a despedida de Keating mantém a gramática audiovisual que o texto fílmico trabalha (vide figura 7). Nem todos seremos capazes de "fazer das nossas vidas algo extraordinário", mas estaremos mais aptos se nos forem oferecidas as condições. A imagem ilustra-o deixando alunos sentados e em atitude submissa em contraponto com alunos que afirmam o seu mote de vida, subindo às carteiras, deixando-se ficar de pé, não obstante a presença do diretor entre eles. A grande diferença entre os dois planos em que nos são mostrados alunos de pé sobre as carteiras está na atitude: se no primeiro estão afirmativos e assertivos, aqui parecem "fazer o luto" por Neil (que se suicidou) e pelo despedimento de Keating; se antes a mise-en-scène nos sugeria um triângulo equilátero, agora, claramente confirma-nos o círculo da completude. Bem ou mal, o ensino para a inclusão em sociedade foi alcançado, caberá a cada um deles, exercê-lo. 


\section{RevistAleph}

\section{Welton ou da tradição convicta}

Welton é uma instituição secular que se afirma em "quatro pilares": Tradição, Honra, Disciplina, Excelência. O texto fílmico abre com a apresentação de Welton, uma instituição de ensino que afirma convictamente a tradição, não comporta a experiência nem o novo como lugar de (re)construção epocal (TAGUIEFF, 2004). Welton forma, a sucessivas gerações, as elites da sociedade, advogados, banqueiros, médicos. O ensino-aprendizagem é conforme a natureza conservadora que pune o desvio à norma. $\mathrm{O}$ desvio é punido com o castigo físico, com a ameaça de expulsão, que é vista e considerada, por Welton, a representação da excomunhão da ágora, como um ostracismo social presente, mas também a nível social, no tempo futuro.

Tradição, Honra, Disciplina e Excelência estão representados, no texto fílmico, do ponto de vista da iconologia da imagem, na geografia do edifício e do espaço em que se inscreve, nos rituais, nas cerimônias, nos uniformes, nas insígnias. Mas os quatro pilares não compreendem o indivíduo - a luz, ícone do conhecimento, não convoca a descoberta, ao crescimento interior do sujeito, antes, é vinculada ao coletivo estabelecido quando a sua carga de significação é lida no movimento conjunto de todos os alunos se levantarem, em simultâneo, e ecoarem os pilares em uníssono, durante a cerimônia de abertura do ano letivo, permitindo-nos a leitura de uma certa morte do indivíduo.

Considerado organicamente, enquanto lugar de ensino, Welton impregna a lecionação da mesma rigidez das suas paredes e dos seus rituais: as aulas estabelecem um distanciamento entre docentes e discentes, que se traduz na metodologia de ensino e permite a leitura de uma nivelação no eixo superior vs. inferior. 


\section{RevistAleph}

\section{Keating ou Oh Captain, my Captain!}

A personagem de Keating deve ser vista considerando sempre que foi aluno de Welton. Isto é, também Keating foi educado no conservadorismo da instituição. Assim, a sua entrada em cena, mais do que uma apresentação de personagem é um statement. Ao assobiar e sugerir que the chamem "Oh Captain, my Captain!", Keating revela-se em clara e consciente ruptura com a rigidez de Welton. Contudo, a frase encerra algo mais: estamos perante um excerto de um poema de Walt Whitman dedicado a Abraham Lincoln. O verso tem, de alguma forma, o carácter enaltecedor e mesmo epopeico e não deixa de convocar uma ambiência de relação bélica fazendo uso do Oh Captain, my Captain!

Contextualizada, a frase fílmica tem uma dúplice leitura: com o chamamento, Keating convoca à revolta contra a ordem estabelecida, convoca à descoberta de si mesmo, e convoca à defesa dos valores e convicções individuais, à libertação da ordem imposta, sob comando, é certo... Oh Captain, my Captain!... Mas aqui, como na Guerra da Independência, é o comando do Oh Captain, my Captain! que conduz à libertação do indivíduo, à defesa dos valores e ideais próprios. De algum modo, Welton revela-se um espaço de ensino conservador, mas, ao mesmo tempo capaz de, inadvertidamente, gerar a independência e a ruptura com o conservadorismo e, contudo, ainda no respeito pelos mesmos quatro pilares que o regem: Tradição, Honra, Disciplina e Excelência.

A Tradição está presente em Keating na sua defesa pela poesia, não como lugar do literário, mas como lugar de exercício da paixão da verdadeira humanidade; A Honra está presente em Keating, na sua defesa dos seus ideais; A Disciplina está presente em Keating, não como instrumento de repressão, mas como instrumento de prossecução dos seus ideais; A Excelência está presente em Keating, na forma como concebe a relação docente/discente que se expressa num contexto de paideia. Em Keating, Tradição, Honra, Disciplina e Excelência somente podem ser compreendidos como vertentes de ensino e sociedade se direcionados para a construção e completude de cada indivíduo, afastado do conservadorismo e revelando-se mais atento a uma modernidade, no contexto baudelairiano (BAUDELAIRE, 2013), de plenitude do efêmero expresso na mensagem Carpe Diem - Aproveitem o dia, na evocação dos versos de Walt Whitman: "Apanha os botões de rosa enquanto podes/O tempo voa./ E esta flor que hoje sorri/Amanhã estará moribunda." 


\section{RevistAleph}

Keating é uma personagem redonda (FIELD, 1979). Apresenta-se como uma personagem complexa, com profundidade, senão exatamente no curso da curva dramática clássica deste texto fílmico (não temos notícia da vida da personagem após o suicídio de Neil), na forma como vivencia e representa o conceito de ensino e sociedade, modos de revolta e libertação considerados como descoberta e afirmação dos seus próprios valores e ideais e, como adverte Keating, essa escolha por si mesmo, é uma via dolorosa. Keating adverte para a dificuldade de se manter fiel a si mesmo perante o olhar dos outros.

A personagem de Keating revela-se uma personagem trágica na acepção dos conceitos aristotélicos. A sua intervenção medeia a libertação de Neil, mas medeia, em consequência, o suicídio do jovem. Construindo uma linha dramática trágica, como imitação das ações mais nobres dos homens nobres (ARISTÓTELES, 2004), Keating conduz os jovens quase num exercício psicanalítico, ao conhecimento de si mesmos. No caso, de Neil, de modo mais evidente e dramático, essa descoberta e o assumir da sua verdade acabou por conduzir ao suicídio, cumprindo-se assim, a profecia de Keating que adverte (aqui a personagem funciona como coro trágico) que essa pode ser uma escolha difícil.

A personagem de Keating mantém-se, ainda, muito próxima do cânon da tragédia grega: a sua missão está-lhe atribuída, não corresponde a uma escolha de livre arbítrio (SANTO AGOSTINHO, 2018). Antigo aluno de Welton, formado de acordo com os quatro pilares da instituição, sem que nos seja dito como, Keating é subtraído à própria missão de Welton.

\section{O Clube dos Poetas Mortos ou da Gruta}

A recriação do Clube dos Poetas Mortos, na antiga gruta, decorre sem o conhecimento da personagem de Keating e acabará por ter consequências trágicas na vida dos jovens. Neste ponto, o texto fílmico parece chamar a atenção para a necessidade de contextualização a cada momento. O que, na geração de Keating, deu lugar a um homem com sede de verdadeira vida, vivida plenamente, na geração dos seus alunos, deu lugar a uma catarse incontrolável.

A gruta deste texto fílmico não deixa de nos convocar a gruta da Alegoria da Caverna (PLATÃO, 2017) a par da tradição judaico-cristã, e fá-lo a dois níveis, desde logo na renovada ausência do feminino e, ainda, na concepção de que a poesia, a dança e as 


\section{RevistAleph}

músicas, no interior da gruta, conduzirão ao conhecimento que o homem não está preparado para suportar: ao homem, na gruta, cabe a compreensão das sombras, não dos arquétipos. Assim, o texto fílmico sugere-nos que mais do que a Verdade e a Poesia, é Welton que habita a gruta. Era uma Tradição (ainda que transgressiva) que já vinha do tempo de Keating; era lugar de Honra, pertencer ao Clube dos Poetas Mortos era honrar os maiores de entre os homens, os poetas.

A atual sociedade neoliberalista considera o eixo aluno/professor na perspectiva de que ao aluno é oferecido o estudo e ao professor cabe o papel de transformador dos seus discentes, consentindo na falsa ideia de que cabe ao professor a educação para lá da sala de aula.

Esta começa por ser a primeira questão que o texto fílmico nos coloca: qual a relação docente/discente? Qual a extensão que é aceitável imputar a esta relação orgânica? Como enquadaramos o binômio professor/aluno no trinômio família(sociedade)/professor-(ensino)/ aluno-(aprendizagem)?

O Clube dos Poetas Mortos evidencia duas linhas pedagógicas diferenciadas: por um lado, o colégio e os valores conservadores que defende protagonizados na personagem do diretor e/ou do professor de latim e, por outro lado, a atitude diferenciada mais afetiva e flexível do professor de literatura inglesa.

\section{O Clube dos Poetas Mortos ou O Ensino e a Sociedade}

A narrativa fílmica leva-nos a indagar, que tipo de ensino e que tipo de sociedade almejamos alcançar. Recuperando o ponto de partida da presente reflexão, acreditamos que a análise do texto fílmico $O$ Clube dos Poetas Mortos, faz sobressair que estamos perante um movimento dialético no sentido hegeliano (HEGEL, 2014), com a particularidade que se desdobra a dois níveis, o subjetivo (Ensino) e o objetivo (Sociedade). Para Keating, o ensino é considerado como crescimento interior e afirmação de identidade. Assim, excluise da práxis do docente, o autoritarismo ou a demonstração de um conhecimento. O Ensino é autodescoberta interior e, nisso, não será inocente a opção dramatúrgica pela personagem de um professor de Literatura que ensina Poesia. Recuperando a intencionalidade cosmogônica (e, inevitavelmente, catártica) da poesia. Keating faz-se representação do Ensino: apresentador de uma tese (a poesia shakespeariana tal como ele 


\section{RevistAleph}

a entende), que se revelará antítese (representada pela rejeição primária por parte dos alunos) e que, uma vez constituída descoberta de si, se revelará síntese (representada no poema criado pelo aluno que de tal parecia incapaz).

Num segundo plano, reencontramos o mesmo movimento dialético (HEGEL, 2014), mas agora objetivado na Sociedade. Os valores conservadores de Welton (tese), subvertidos pelas atitudes de valores de Keating e dos seus alunos, que nem o colégio nem os pais parecem compartilhar (antítese) e, finalmente, a sua superação (síntese) figurados quer no suicídio de Neal, quer no despedimento de Keating.

Esta duplicidade de movimentos dialéticos que o texto fílmico comporta legitima a leitura de uma Hiper textualidade a par de uma não linearidade que caracterizam o atual momento tecnológico. Tanto um movimento quanto o outro são expressão da Era Digital. A libertação da linearidade inerente à escrita (McLUHAN, 1972) coloca-nos quer num universo de sentido que recupera a imagem como lugar de expressão e de apreensão do real envolvente. Desta forma, hoje em dia, convivemos com um Ensino que se faz subjetivo e construtor do seu próprio percurso. Os nossos jovens, em ambiente digital, abandonam a linearidade (que o discurso do professor ainda representa) e encontram-se a cartografar a sua aprendizagem (linearidade, identidade) de forma não-linear, na alternância de percursos de aprendizagem próprios (e de que a Reforma de Bolonha é um exemplo, na sua proposta mais essencial). A Hiper textualidade de que o ensino se faz construir é um ato de livre arbítrio e de disponibilidade à descoberta: não sigo um caminho pré-definido, construo o meu caminho e faço-o a cada momento, ou seja, prisioneira da paixão: a Hiper textualidade é a representação do efêmero baudelairiano. Um presente que se faz passado e futuro a um só tempo (BAUDELAIRE, 2013), efêmero, portanto, irrepetível, do mesmo modo que a aprendizagem em ambiente digital é não-linear, hipertextual e, assim, irrepetível (mas, nem por isso efémera).

Somos, pois, a concluir que os conceitos de Ensino e Sociedade convocados pelo texto fílmico $O$ Clube dos Poetas Mortos, se mantêm ontológica e fenomenologicamente mesmo que sejam considerados à luz da nossa época. Vale perguntar o que diferencia o Ensino e a Sociedade representadas quando confrontadas com a atualidade? Na sua essência permanecem iguais, o artefacto tecnológico é que se alterou. Tecnologia reporta para dois étimos latinos: téchné e logos (PETERS, 1983: 224-226). Aristóteles define a téchné como uma característica vocacionada para a produção (poietike) com origem na experiência 


\section{RevistAleph}

individual (empeiria) - tornada téchné quando generalizada (ARISTÓTELES, 2012). Ou seja, a técnica reporta-se ao saber fazer, dado que logos é entendido como princípio subjacente e organizador do universo (HERACLITO, 2006). Por outras palavras, a tecnologia não pode ser confundida com a ferramenta nem deve ser dissociada da natureza ou do homem (HEIDEGGER, 1977). A tecnologia intermedeia a ação do homem com a natureza, nesse sentido, ela é a sua própria natureza. O homem é tecnológico (HEIDEGGER, 1977).

Damos assim, como demonstrada a nossa pergunta de partida, mas abre-se-nos, no horizonte, aos dias de hoje, uma talvez mais importante: onde nos está a levar a tecnologia num mundo em que, por via da nossa ainda (in)capacidade científica e tecnológica, a Sociedade se vê confrontada (confinada/ameaçada) com uma situação pandémica (Covid 19) que reposiciona, transversalmente (e não por opção), o Ensino para o ambiente digital? Do presencial o Ensino viu-se confrontado com o b-Learning, com o e-learning? Do presencial ao online, a nossa Sociedade e o nosso Ensino sobrevivem, por estes dias (e no desconhecimento de um terminus), como Ensino e Sociedade online. Pela primeira vez, na longa caminhada da Humanidade, a ferramenta (a técnica/a tecnologia) não se interpõe entre nós e o real. Constitui-se barreira que nos salva impedindo-nos o contato com o real. Valeria a pena, sob o espírito de $O$ Clube dos Poetas Mortos, recordar Oh Captain, my Captain que, mais do que nunca, vivemos Carpe Diem, ganhando um novo e assustador sentido a máxima de Melvin Kranzberg (1917-1995): A tecnologia não é boa, nem má; mas também não é neutra. Hoje, mais do que nunca, será o momento para que a Sociedade e o Ensino se façam reflexão do que essa máxima encerra. Ao mesmo tempo que somos chegados a uma Sociedade e a um Ensino em que se rejeita liminarmente a exclusão de mulheres. Hoje, as mulheres são discentes, são docentes, mas foram precisos séculos para que conquistassem esse patamar. Destacam-se, ganham espaço e visibilidade, ainda que sempre a contramão e acumulando o aprender e o ensinar com o tradicional papel na sociedade - esposas e mães (donas-de-casa), nem o avanço tecnológico, nem a atual crise pandémica retiraram o gênero ao fazer, ser, estar em sociedade. Longe estamos ainda do lugar da almejada equidade. Mesmo quando a situação nos leva para o backstage, ocultos que somos atrás de ecrãs, o gênero que prevalece, até mesmo em virtude da linguagem, é o masculino: está-se no teletrabalho, está-se no online, está-se no computador, está-se no online... Vale perguntar: em plena pandemia que nos assola, sejamos homens ou mulheres, onde estão as mulheres? 


\section{RevistAleph}

\section{Bibliografia}

ARISTÓTELES. A Poética. Lisboa: Edição Fundação Calouste Gulbenkian, 2004.

ARISTÓTELES. Ética a Nicómano. Lisboa: edições Universitárias Lusófonas, 2012

BARTHES, Roland. Mitologias. Lisboa: Edições 70, Almedina, 2007.

BAUDELAIRE. O Pintor da Vida Moderna. Lisboa: Nova Veja, 2013.

D’HOLLANDA, Francisco. Tratado da Pintura Antiga. Porto: Renascença Porto,1918.

FIELD, Syd. Screenplay: The Foundations of Screenwriting. USA: Dell Publishing Company, 1979.

HEGEL, Friederich. Fenomenologia do Espírito. Brasil: Editora Vozes, 2014.

HEIDEGGER, Martin. O Ser e o Tempo. Brasil: Editora Vozes, 2009.

HEIDEGGER, Martin. The Question Concerning Technology and other essays. New York, London: Garland Publishing, Inc, 1977.

HERACLITO. Fragmentos contextualizados. Lisboa: INCM - Imprensa Nacional Casa da Moeda, 2006.

MCLHUAN, Marshall. A Galáxia de Gutenberg - a formação do homem tipográfico. Brasil:

Companhia Editorial Nacional - Editora da Universidade de São Paulo, 1972.

METZ, Christian. O Significante Imaginário - Psicanálise e Cinema. Lisboa: Livros Horizonte, 1980.

MULVEY, Laura. Visual and other Pleasures. USA: Palgrave, 2009.

PLATÃO. A República. Lisboa: Fundação Calouste Gulbenkian, 2017.

PETERS, F.E. Dicionário de Termos Filosóficos Gregos - um léxico histórico. Lisboa: Fundação Calouste Gulbenkian, 1983.

TAGUIEFF, P-A. Le Sens du Progrés. Paris: Flammarion, 2004.

SANTO AGOSTINHO. O Livre Arbítrio. Rio de Janeiro: Teodoro Editor, 2018.

Videografia:

Clube dos Poetas Mortos. Realização de Peter Weir. EUA, 1989.

Data do envio: $29 / 05 / 2020$

Data do aceite: 03/06/2020. 